\title{
The Distribution Hearing Loss in Elderly Patients at Sanglah Hospital in Denpasar since 2011-2014
}

\author{
Made Wiranadha \\ Department of otorhinolaryngology, Medical Faculty of Udayana university, Sanglah Hospital, Denpasar, Indonesia
}

\begin{abstract}
Introduction: the purpose of this study to determine the distribution of hearing loss in the elderly patients at Sanglah hospital 2011-2014. Materials and methods: elderly patients aged 60 years and over with hearing loss who come to the polyclinic ENT Sanglah Hospital were the period January 2011 to December 2014. The patients who met the inclusion criteria included in the study sample study conducted pure tone audiometric examination. Results: elderly patients with male sex experience more hearing loss than women manifold. Discussion: sensorineural hearing loss was mostly found in patients in group age of 60-70 years old over all patients vising polyclinic during the periode between january 2011 to december 2014.
\end{abstract}

Keywords: Elderly, sensorineural, hearing loss

\section{Introduction}

Hearing loss is a partial or total inability to hear sound in one or both ears. The distribution of hearing loss is categorized into three type which are conductive hearing loss, sesnsorineural hearing loss and also mixture of both type. It is also graded by level of severity: mild, moderate, severe and very severe. The definition of elderly is person who has attained the age of 60 years and above. In older people the process of degeneration on the entire structure so that the ear hearing loss can occur on the outer ear, the middle ear and the inner ear. The common type of hearing loss in the elderly is sensorineural hearing loss but can also be a mixture or conductive hearing loss. This study is aimed to shows the distribution of hearing loss in the elderly patient, to explain in more detail and to obtain data as future reference plan the action of the prevention and treatment of elderly patients.

\section{The Method}

This study design was retrospective descriptive study by taking secondary data from medical records of elderly patients with hearing loss who visited to policlinic ENT Sanglah Hospital.

Variable research: hearing loss is a partial or total inability to hear sound in one or both ears. Enforcement of diagnoses obtained from history taking, examination mainly through examinations pure tone audiometric, age is a long-life, calculated from the year of birth, gender is a characteristic anatomy and physiology of male or female, the type of hearing loss verified by a comparison between the $\mathrm{AC}$ and $\mathrm{BC}$, Type of hearing loss described through a comparison between $\mathrm{AC}, \mathrm{BC}$ and the gap between the $\mathrm{AC}-\mathrm{BC}$. $\mathrm{BC}$ obtained on conductive hearing loss $<25 \mathrm{~dB}, \mathrm{AC}>25 \mathrm{~dB}$ and there is no gap between the AC-BC. On the mixture obtained hearing loss $\mathrm{BC}>25 \mathrm{db}, \mathrm{AC}>\mathrm{BC}$ and obtained their $\mathrm{AC}-\mathrm{BC}$ gap. And on sensorineural hearing loss obtained $\mathrm{AC}$ and $\mathrm{BC}>25 \mathrm{~dB}$, is obtained AC-BC gap, degree of severity of hearing loss and hearing loss is based on the results of pure tone audiometry were divided into mild, moderate, severe, very severe. The degree of hearing loss to the ISO standards, namely: $0-25 \mathrm{~dB}$ normal, mild hearing loss $26-40 \mathrm{~dB}, 41-$ $55 \mathrm{~dB}$ moderate hearing loss, $56-70 \mathrm{~dB}$ moderate to severe hearing loss, 71-90dB severe hearing loss, $>90 \mathrm{~dB}$ very severe hearing loss, ear side which experience hearing loss, called unilateral when only one side of the ear experience and bilateral hearing loss if ear hearing loss on both sides. The study population was all elderly people with hearing loss who come to policlinic ENT division neurotologi Sanglah Hospital and has been examined pure tone audiometry

\section{Data Analysis}

Data was taken from the medical records of elderly patients with hearing loss who come to policlinic ENT Sanglah Hospital, Denpasar during the period January 2011 to December 2014. The results of the examination are recorded in the data collection sheets for subsequent analysis. The results of the study are presented descriptively in tables .

\section{Results}

Based on table 1, a total of 56 elderly patients with hearing loss or a total of $58.3 \%$ were male and 40 patients or $41.7 \%$ are female.

Table 1: Distribution of hearing loss and elderly patients by

\begin{tabular}{|c|c|c|}
\multicolumn{3}{c|}{ sex } \\
\hline Sex & $n$ & $\%$ \\
\hline Male & 56 & 58,3 \\
\hline Female & 40 & 41,7 \\
\hline Amount & 96 & 100 \\
\hline
\end{tabular}

Table 2 showed that 52 elderly patients with hearing loss or by $54.2 \%$ aged $60-70$ years, 36 elderly patients with hearing loss or $37.5 \%$ aged $71-80$ years, 5 elderly patients with hearing loss or 5.2\% aged $81-90$ years and 3 elderly patients with hearing loss or $3.1 \%$ over the age of 91 years.

Table 2: Distribution of elderly people with hearing loss by

\begin{tabular}{|c|c|c|}
\hline age \\
\hline Age (years) & $\mathrm{n}$ & $\%$ \\
\hline $60-70$ & 52 & 54,2 \\
\hline $71-80$ & 36 & 37,5 \\
\hline $81-90$ & 5 & 5,2 \\
\hline$>91$ & 3 & 3,1 \\
\hline Amount & 96 & 100 \\
\hline
\end{tabular}

\section{Volume 6 Issue 2, February 2017 www.ijsr.net}




\section{International Journal of Science and Research (IJSR) \\ ISSN (Online): 2319-7064}

Index Copernicus Value (2015): 78.96 | Impact Factor (2015): 6.391

Table 3 showed that 142 with the results of audiometric examination sensorineural hearing loss, or by $74.7 \%, 15$ with conductive hearing audiometric examination or by $7.9 \%$, and 33 with the results of audiometric examination hearing loss mixture or $17.4 \%$

Table 3: Distribution of hearing loss and elderly patients based on the type of hearing loss

\begin{tabular}{|l|l|l|}
\hline \multicolumn{1}{|c|}{ Type of hearing loss } & \multicolumn{1}{c|}{$n$} & \multicolumn{1}{c|}{$\%$} \\
\hline Sensorineural hearing loss & 142 & 74,7 \\
\hline Conduction hearing loss & 15 & 7,9 \\
\hline Mixture hearing loss & 33 & 17,4 \\
\hline
\end{tabular}

Based on Table 4 obtained 13 elderly patients with hearing loss or $13.5 \%$ experiencing mild hearing loss with a range of intensities between $26-40 \mathrm{~dB}, 26$ patients, or $27.1 \%$ experiencing moderate hearing loss with a range of intensities between $41-55 \mathrm{~dB}, 31$ elderly patients with hearing loss or by $32.3 \%$ who experience hearing loss was heavy with intensity ranges between $56-70 \mathrm{~dB}, 14$ elderly patients with hearing loss or $14.6 \%$ experiencing severe hearing loss with a range of intensities between $71-90 \mathrm{~dB}$ and there are 12 elderly patients with hearing loss or $12.5 \%$ were experiencing very severe hearing loss with intensity above $90 \mathrm{~dB}$.

Table 4: Distribution of hearing loss and elderly patients based on the degree of hearing loss

\begin{tabular}{|l|c|c|}
\hline \multicolumn{1}{|c|}{ Level of hearing loss $(\mathrm{dB})^{\prime}$} & $n$ & $\%$ \\
\hline Mild hearing loss, 26-40dB & 13 & 13,5 \\
\hline Moderate hearing loss, $41-55 \mathrm{~dB}$ & 26 & 27,1 \\
\hline Severe moderate hearing loss, 56-70dB & 31 & 32,3 \\
\hline Severe hearing loss, 71-90dB & 14 & 14,6 \\
\hline Very severe hearing loss, >90dB & 12 & 12,5 \\
\hline Amount & 96 & 100 \\
\hline
\end{tabular}

Based on Table 5 obtained eight elderly patients with hearing loss or $8.3 \%$ on one side of the ear or unilateral and 88 elderly patients with hearing loss or by $91.7 \%$ on both sides of the ear or bilateral.

Table 5: Distribution of elderly people with hearing loss by the experienced ear hearing loss

\begin{tabular}{|c|c|c|}
\hline Ear side who experience hearing loss & $n$ & $\%$ \\
\hline Unilateral & 8 & 8,3 \\
\hline Bilateral & 88 & 91,7 \\
\hline Amount & 96 & 100 \\
\hline
\end{tabular}

\section{Discussion}

This study is a retrospective descriptive study by taking the secondary data of elderly patients with hearing loss who came to the ENT department of Sanglah the period January 2011 to December 2014. A total of 96 patients met the inclusion criteria of research and then conducted a descriptive analysis. Lee and Karen, in 2010 found a link between the age of the increase in the hearing threshold of the elderly. The average hearing threshold value decreases $1 \mathrm{~dB}$ each year at the age of 60 years and above and obtained an increase in the hearing threshold at frequencies 4000 and $8000 \mathrm{~Hz}$

Shapiro, 2004 reported that the hearing loss is included in the top three chronic conditions often experienced by the elderly.
Its prevalence increases with age. The prevalence of hearing loss in the $65-75$ year age range is $20-40 \%$ and above 75 years of age increased by $40-66 \%$ prevalence. Corna, 2009 reported that the prevalence of hearing loss in the elderly patients increases with age. Research conducted in Australia by Mitchell in 2011 obtained of elderly people aged 60-69 years the prevalence of hearing loss $28.7 \%$, in the group of elderly people aged 70-79 years the prevalence of hearing loss by 55\% and in the elderly group aged 80-89 the prevalence of hearing loss by $79 \%$.

\section{Conclusion}

In this study can be concluded that the distribution of elderly patients with hearing loss during the period January 2011December 2014 which came to Sanglah Hospital is as much as 96 elderly patients with gender distribution, include men by $58.3 \%$ with an age range of $60-70$ years most of $54.2 \%$ with most types of hearing loss and sensorineural types of $74.7 \%$ which are abundant on both sides of complaints hearing loss ears or bilateral amounted to $91.7 \%$.

\section{References}

[1] Salonen Jaakko. Hearing impairment and tinnitus in the elderly. University of Turku.Finland. 2013:p.1-68.

[2] Hall, JW. and Antonelli, PJ. Assessment of peripheral and central auditory function. In: Bailey, BJ., Johnson, JT. Editors. Head \& Neck Surgery - Otolaryngology $4^{\text {th }}$ ed. Philadelphia: Lippincott Williams \& Wilkins. 2006:p. 1927-41.

[3] Moller, AR. Hearing: Anatomy, Physiology, and Disorders of the Auditory System $2^{\text {nd }}$ ed. London: Elsevier Inc. 2006:p.3-17

[4] Shapiro. N, Shekelle. Quality indicators dor the management of hearing loss in vulnerable elder persons. UCLA head and neck surgery.United States of America. 2004:p.1-22

[5] Solheim Jorunn. Hearing loss in elderly. University of Oslo.Norwegia. 2013:p.1-122.

[6] Mitchell, Gopinath. Five-year incidence and progression of hearing impairment in an older population. Ear Hear 2011;32:p.251-57.

[7] Duthey Beatrice. Priority Medicines for Europe and the World "A Public Health Approach to Innovation". 2013:p.1-50.

[8] Malinoff, Weinstein. Measurement of hearing aid benefit in the elderly. Ear Hear. 1989;10(6):p.354-56.

[9] Lin. R, Thorpe. R, Gordon-Salant, Ferrucci. L. Hearing loss prevalence and risk factors among older adults in the United States.Journal of Gerontology: Medical Sciences; 2011;66(5):p.582-90.

[10] Lieberman. D, Friger. M, Lieberman. D. Visual and hearing impairment in elderly patients hospitalized for rehabilitation following hip fracture. Journal of Rehabilitation Research \& Development. 2004; 41(5):p.669-74.

[11] Hall. J, Lewis. M. Diagnostic, Audiology, Hearing Aids and Habilitation Option. Ballenger's Manual of Otorhinolaryngology Head \& Neck Surgery. BC Decker London. 2002(1):p. 1-3. 


\section{International Journal of Science and Research (IJSR) \\ ISSN (Online): 2319-7064 \\ Index Copernicus Value (2015): 78.96 | Impact Factor (2015): 6.391}

[12]Fook. L, Morgan. R. Hearing impairment in older people: a review. Postgraduation Med Journal. 2000;76:537-41.

[13]Loh. KY, Elango. Hearing impairment in elderly. Malaysia medical journal. 2005; 60(4):p.526-30.

[14] Gussekloo, Bont, Eekhof. Auditory rehabilitation of older people from the general population. Br.J.Gen.Pract. 2003; 53(492):p.536-40.

[15] Helvik, Jacobsen, Activity limitation and participation restriction in adults seeking hearing aid fitting and rehabilitation. Disabil.Rehabil. 2006;28(5): p.281-88.

[16]Corna, Wade, Streiner. Corrected and uncorrected hearing impairment in older Canadians. Gerontology Med Journal. 2009;55:p.468-76.

\section{Author Profile}

Wiranadha MD is a staff of ENT department at Udayana University Sanglah general hospital Bali Indonesia, since 2004 until now. He has big interest and give big support in this study. He is now still focus on neurootology division. 